\title{
On the feasibility of watertight face-sealed window-wall interfaces
}

\author{
Stéphanie Van Linden ${ }^{1, *}$, Nathan Van Den Bossche ${ }^{1}$ \\ ${ }^{1}$ Ghent University, Faculty of Engineering and Architecture, Building Physics Group, Belgium
}

\begin{abstract}
Watertightness is still a major source of concern in the performance of the building envelope. Even very small deficiencies can cause a significant amount of water leakage which may result in structural degradation or malfunctioning of the insulation. The risk of water infiltration is highest at joints between different building components and in particular at the window-wall interface due to the complexity of these joints. This paper focuses on the performance of different solutions to ensure the watertightness of the window-wall interface, e.g. self-adhesive foils, liquid applied coatings, prefabricated frames, self-expanding sealing strips. The performance of these solutions is evaluated for different wall assemblies, i.e. ETICS, masonry, structural insulated panels and woodframe construction. Laboratory experiments were conducted on a full-scale test setup with a window of $1,01 \mathrm{~m}$ high and $0,56 \mathrm{~m}$ wide. Test results showed that it is not evident to obtain watertight face-sealed window-wall interfaces without an additional airtight layer or drainage possibilities. Water ingress was often recorded at lower pressure differences.
\end{abstract}

\section{Introduction}

One of the primary functions of exterior walls and claddings is to prevent rainwater from entering and reaching the interior parts of the walls. However, it is observed that claddings are usually not completely watertight [1]. According to the ASHRAE Standard 160, a penetration rate of $1 \%$ of the rain impinging on the cladding should be considered when evaluating the moisture control design of a building [2]. Water entering the wall assembly is mainly attributed to the presence of deficiencies at joints around façade details. Research on water resistance of facades showed that it is very difficult to seal these joints completely watertight, in particular at the window-wall interface due to the complexity of these joints, i.e. out-of-plane sealing, presence of corners, ... [3] [4] [5]. Olsson [6] conducted a study to evaluate the water resistance of window-wall connections for three different facades: ventilated composite board as façade, concrete façade with cellular plastic and drained ETICS. All tested façade systems showed water leakages. Many of the observed water leaks were already present without any pressure difference over the wall assemblies. It was stated that the openings through which water leaked were almost imperceptible. The cause of failure was however not specified.

\footnotetext{
* Corresponding author: stephanie.vanlinden@ugent.be
} 
A similar study was conducted by Lacasse et al. [7]. Different window-wall interfaces typically used in wood frame low-rise wall assemblies were evaluated. Half of the tested window-wall interfaces included a "best current practice detail" and the other half included an "upgrade" of detailing the interface including an additional seal joining the window frame to the sheathing board. Significantly lower infiltration rates were measured with the additional seal and backer rod. However, water entry was not entirely eliminated. It was observed that the airtightness of the assemblies was a determining factor for the water entry rate as lower water collection rates were measured for tighter assemblies. Afterwards, the same specimens were evaluated including $90 \mathrm{~mm}$ missing length of sealant and backer rod at the lower and outer corner of the window frame. Significant amounts of water leakage were observed through the deficiency in the sealed window-wall interfaces when subjected to water spray and no pressure differential. This implied that gravity alone resulted in water entry.

The objective of this study is to evaluate the performance of different sealing methods. Laboratory experiments were conducted to determine the risk of water entry and the impact of faulty workmanship for different installation methods and different wall assemblies.

\section{Test setup and methodology}

\subsection{Test setup}

The driving rain resistance and air leakage of different solutions to seal the window-wall interface were evaluated by means of six test specimens. Figure 1 provides horizontal and vertical section details and a front view of the different window-wall interfaces. Each test specimen was mounted in a steel frame with dimensions $2390 \times 1070 \mathrm{~mm}$ and incorporated a window measuring $560 \times 1010 \mathrm{~mm}$. The steel frames were affixed to a test chamber. The exterior surface of the test specimens was faced to the inside of the test chamber and was exposed to simulated driving rain loads. The interior surface of the specimens was faced to the laboratory and could be observed during the test.

Four different wall construction types were assessed, i.e. concrete (1), masonry $(2,3)$, structural insulated panel (4) and wood-frame construction $(5,6)$. A cladding was only provided for test specimen 5 and 6, i.e. ETICS. The windows were installed either by means of $90^{\circ}$ angle brackets (1), window fixing brackets $(2,3,4)$ or a prefabricated frame $(5,6)$. The joints between the window and the wall were sealed by use of adhesive sealing tapes, a prefabricated EPDM frame, liquid applied coatings and self-expanding sealing strips or a combination of these materials. The performance of both "best practice" specimen (Figure 1) and different variations of each sealing method were tested to evaluate the impact of faulty workmanship on the driving rain resistance of the specimen.

\subsection{Test procedure}

Prior to each watertightness test, the air leakage of the test specimens was measured. The wall assemblies and windows were considered airtight which implies that the measured air leakage was only caused by the window-wall interface. The airflow was measured according to EN 12114 [8] at eight fixed pressure differences, 50 - $100-150$ - 200 - 250 $300-450-600 \mathrm{~Pa}$. The airflow was derived by measuring the pressure difference over a calibrated opening in a diaphragm. The results were curve fitted using the power law to obtain the leakage for each pressure difference and the leakage coefficients, $\mathrm{C}$ and $\mathrm{n}$ :

$$
\mathrm{V}=\mathrm{C} . \Delta \mathrm{P}^{\mathrm{n}}
$$


The watertightness of the test specimens was measured according to EN 1027 [9]. A spraying rack was installed at a distance of $250 \mathrm{~mm}$ from the exterior surface of the specimen. Each specimen was submitted to a static watertightness test using a spray rate of $2 \mathrm{l} / \mathrm{min} / \mathrm{m}^{2}$. The first 15 minutes of water spraying, no pressure difference was created. After these first 15 minutes, the pressure was raised every 5 minutes from 50 - 100 - 150 $200-250-300-450-600-750-900 \mathrm{~Pa}$. The interior surface of the test specimens was visually observed during the test.

1) Butyl tape

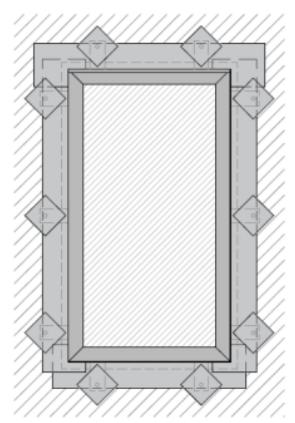

3) EPDM frame

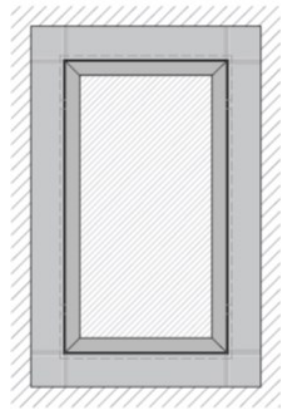

5) Self-expanding sealing strip + liquid applied coating

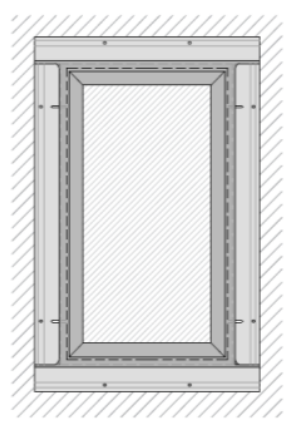

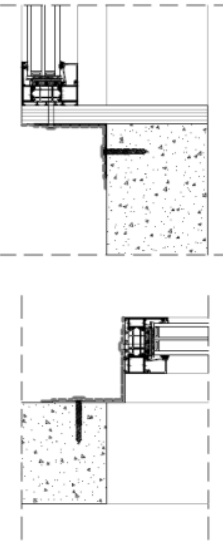
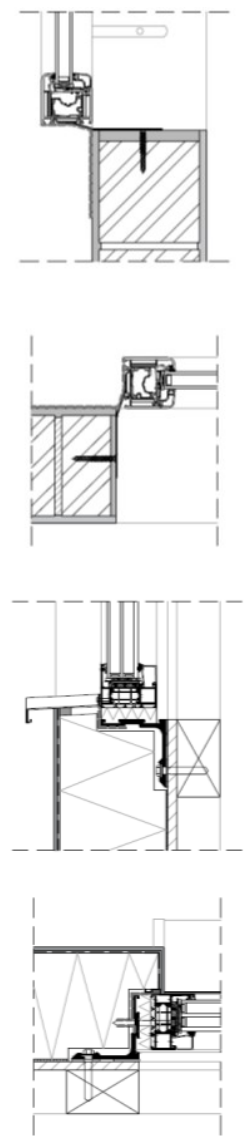

2) Adhesive sealing tape
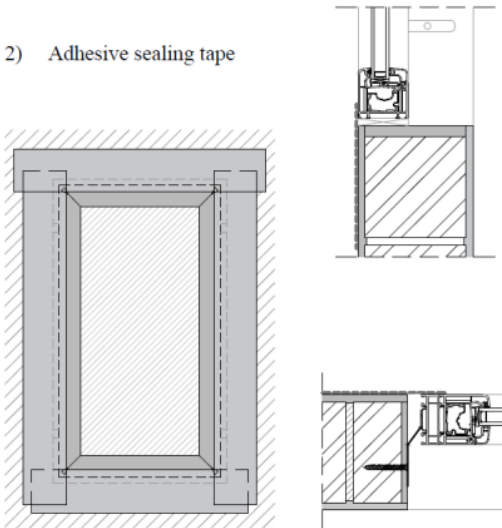

4) Liquid applied coating
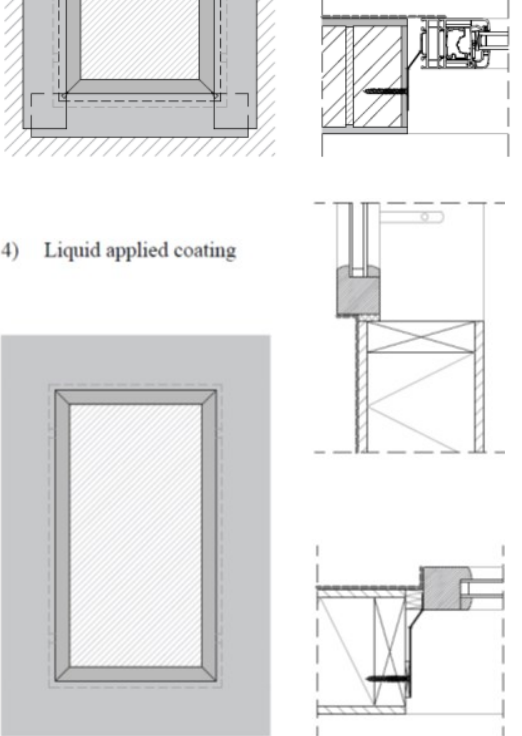

6)

Self-expanding sealing strip + adhesive sealing tape

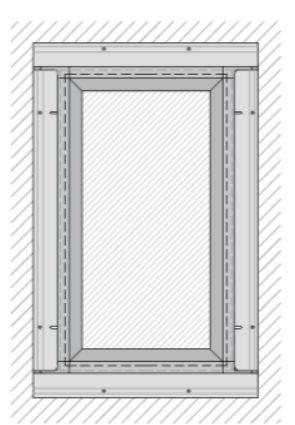

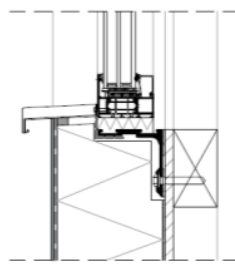

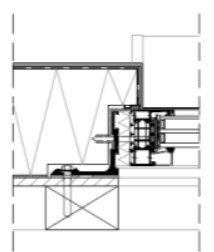

Figure 1: Front view, vertical and horizontal section details of "best practice" test specimen 


\subsection{Classification criteria}

Several European research institutes have determined guidelines for the airtightness of the window-wall interface. Ift Rosenheim [10] prescribes a maximum value for the airtightness of the sealed window-wall interface as a function of the applied pressure difference, i.e. a $<$ $0,1 \mathrm{~m}^{3} /\left(\mathrm{m} . \mathrm{h} .(\mathrm{daPa})^{2 / 3}\right)$. This results in an airflow of $0,29 \mathrm{~m}^{3} / \mathrm{h} . \mathrm{m}$ at a pressure difference of $50 \mathrm{~Pa}$. Van Den Bossche [11] describes a classification method based on $10 \%$ of the overall building air leakage: $3,3 \mathrm{~m}^{3} / \mathrm{h} . \mathrm{m}$ at $50 \mathrm{~Pa}$ as a maximum value $\left(6 \mathrm{~h}^{-1}\right), 1,6 \mathrm{~m}^{3} / \mathrm{h} . \mathrm{m}$ for reasonably airtight buildings $\left(3 \mathrm{~h}^{-1}\right)$ and $0,33 \mathrm{~m}^{3} / \mathrm{h}$.m for passive houses $\left(0,6 \mathrm{~h}^{-1}\right)$. SBR [12] also published guidelines for the maximum air leakage through window-wall interfaces corresponding with three building airtightness classes defined by NEN 2687 [13]: 2,38; 1,$19 ; 0,24 \mathrm{~m}^{3} / \mathrm{h} . \mathrm{m}$ respectively for airtightness class 1,2 and 3 .

To the knowledge of the authors no classification system for the watertightness of window-wall interfaces exists within the European framework. EN 12208 [14], however, describes watertightness classes for windows and doors based on the maximum pressure difference at which no water penetration is observed at the back of the test setup, e.g. class 9A corresponds with no water leakage at a pressure difference of $600 \mathrm{~Pa}$. $600 \mathrm{~Pa}$ is often used as a criteria for the watertightness of sealing materials in Belgium. According to prNBN B 25-002-1:2017 [15], which relates the watertightness classes to a terrain category, base wind speed and building reference height, these materials may then be applied to buildings near the coast with a base wind speed up to $26 \mathrm{~m} / \mathrm{s}$ and a reference height up to 42 m.

\section{Results and discussion}

The performance of both "best practice" specimen and different variations of each sealing method were evaluated. Prior to the watertightness tests, the air leakage of the test specimens was measured. No other airtight layer than the tested sealing materials was installed at the window-wall interface which implies that the applied pressure difference acted entirely over the sealing materials. The measured airflow of all tested specimens was well below the guideline for a very good airtightness class 3, prescribed by SBR, i.e. 0,24 $\mathrm{m}^{3} / \mathrm{h}$.m. The airflow of the different tested variations did not significantly differ from the airflow of the best practice specimens.

Table 1 shows the results of the watertightness tests. The sealing methods were installed in the best possible way by trained installers with the aim of passing the test, meaning that no water leaks may be observed at the interior side of the specimen up to a pressure difference of $600 \mathrm{~Pa}$. However, several attempts and measures were necessary to obtain "best practice" specimens, e.g. seven tests were conducted with the butyl tape before the specimen passed the test. Other variations of the test specimens showed water leaks at low pressure differences. Table 1 shows the most significant results.

Table 1: Results watertightness tests (number between brackets shows amount of tests)

\begin{tabular}{|c|c|c|c|}
\hline Test specimen & Pass/fail & Test specimen & Pass/fail \\
\hline \multirow{3}{*}{$\begin{array}{l}\text { 1. a) Best practice } \\
\text { b) Without } 45^{\circ} \\
\text { c) Tape on top }\end{array}$} & Pass (7) & 2. a) Best practice - adhesive tape & Pass (8) \\
\hline & $0 \mathrm{~Pa}$ & b) Without triangular patches & $200 \mathrm{~Pa}$ \\
\hline & $0 \mathrm{~Pa}$ & c) Larger length of bottom tape & $150 \mathrm{~Pa}$ \\
\hline \multirow{3}{*}{$\begin{array}{l}\text { 3. a) Best practice - EPDM frame } \\
\text { b) Alignment of frame } \\
\text { c) Size of frame }>\text { window }\end{array}$} & Pass (6) & d) Without pressurization & $100 \mathrm{~Pa}$ \\
\hline & $250 \mathrm{~Pa}$ & 4. a) Best practice - coating & Pass (2) \\
\hline & $250 \mathrm{~Pa}$ & b) One layer of coating & $150 \mathrm{~Pa}$ \\
\hline 5. a) Best practice - SESS + coating & Pass (2) & 6. a) Best practice - SESS + tape & Pass (2) \\
\hline
\end{tabular}


b) Without cladding

Pass

b) Without cladding

$0 \mathrm{~Pa}$

The window-wall interface sealed with butyl tape failed when no additional patches were applied on top of the brackets (1b). As the butyl tape did not cover the brackets entirely, small differences in height were apparent causing openings at the sides of the brackets. The square shaped and diagonally applied patches ensured that water which was running off the wall continued flowing down along the oblique sides of the square patches. The same phenomenon was observed when the window-wall interface sealed with self-adhesive tape was tested without triangular patches $(2 \mathrm{~b})$. These patches were applied to the corners of the windows where a horizontal tape and a vertical tape overlapped. Also when the length of the tape at the bottom of the window was increased, creating additional overlaps between the horizontal and vertical tapes, water leaks were (2c). The largest impact on the watertightness of the tapes was observed when the tapes were not pressurized with a pressure roll after application (2d). The tapes were pressure-sensitive which means that the glue is activated when sufficient pressure is applied. In case the tapes were insufficiently pressurized, water leaks were already visible at a pressure difference of $100 \mathrm{~Pa}$ at the bottom of the window.
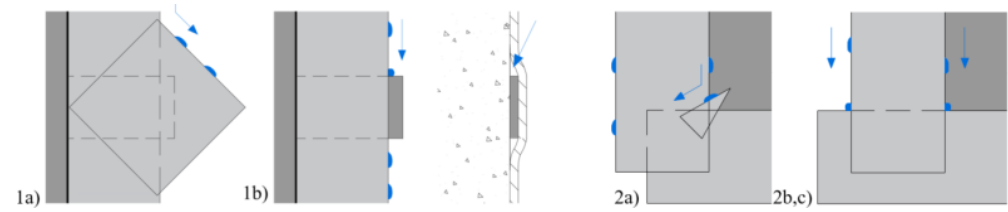

Figure 2: Impact of tape patches: front view (1a,b and 2a,b,c), vertical section of $1 \mathrm{~b}$

Also the position of the sealing materials relative to the exterior surface of the window had a significant impact on the watertightness. The butyl tape showed water leaks without any pressure difference when the top horizontal tape was adhered on top of the window frame instead of the front of the window frame (1c). Also the alignment of the EPDMframe relative to the window was an important factor (3b). Water leaks were already observed at a pressure difference of $250 \mathrm{~Pa}$ when the top and bottom part of the EPDM frame were positioned respectively more inwards and outwards relative to the exterior surface of the window. Water was able to stagnate on top of the window in front of the tape and on top of the bottom tape causing infiltration when a pressure difference over the wall was applied. Also when an incorrect size of the EPDM-frame was applied (3c), water leaks were observed at $250 \mathrm{~Pa}$. The size of the frame was larger than the perimeter of the window frame causing an opening at one of the corners which could not be sufficiently adhered.
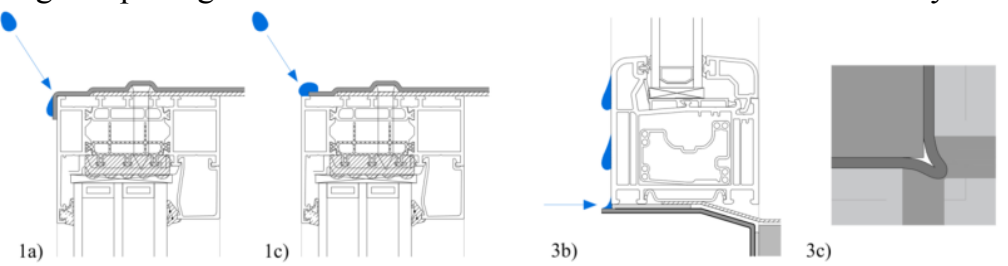

Figure 3: Impact of alignment of tape (1c) and EPDM-frame (3b) and size of frame (3c)

A liquid coating was applied to both specimen 4 and 5. When two layers of the coating were applied, specimen 4 passed the test. When only one layer was applied however (4b), water was able to leak through very small openings in the coating starting at a pressure difference of $150 \mathrm{~Pa}$. Specimen 5 passed the test both with and without an ETICS cladding. When the coating of specimen 5 without cladding was replaced by a tape (6b), however, water infiltration occurred without any pressure difference. Stagnating water on top of the 
bottom part of the window fixing frame caused an additional pressure on the sealing materials resulting in infiltration through the tapes. When, however, an ETICS cladding and self-expanding sealing strips were installed in front of the tapes sealing the joint between the insulation and the window frame, no water leaks were observed. This suggests that the conducted waterightness tests without cladding and any additional airtight layer at the interior side of the building envelope, may be considered as a worst-case scenario.

\section{Conclusion}

The air- and watertightness of different methods to seal the window-wall interface i.e. selfadhesive tapes, prefabricated EPDM-frame, liquid applied coating and self-expanding sealing strip, was evaluated. The sealing materials were installed in the best possible way. Additionally, the performance of different variations of each sealing method was evaluated. The measured airflow of all tested specimen, including different variations, was smaller than $0,24 \mathrm{~m}^{3} / \mathrm{h}$.m which is prescribed as a guideline by SBR for a very good airtightness. For all sealing materials, several attempts and measures were necessary to obtain a "best practice" specimen, i.e. no water leaks up to a pressure difference of $600 \mathrm{~Pa}$. Other variations of the test specimen already showed water leaks at low pressure differences. It should be noted that the specimen were tested as a worst-case scenario, without additional airtight layer and water was sprayed directly onto the sealing materials. The results, however, show that it is not evident to obtain watertight face-sealed window-wall interfaces. A safe approach is to assume that water will penetrate. Improvement of the watertightness of the window-wall interface may be obtained by installing an additional airtight layer and reducing the airtightness of the sealing materials, which may reduce the acting pressure difference over the sealing materials. Additionally, the direct rain load on the sealing materials should be reduced by providing a rainscreen in front of the sealing materials and by providing drainage possibilities.

\section{References}

[1] A. Ten Wolde, Journal of Testing and Evaluation, 39, no. 1, pp. 19428-2959, (2011)

[2] ASHRAE, Ashrae Standard 160-2016 (2016)

[3] Canada Mortgage and Housing Corporation, Technical Series 03-125, (2003)

[4] M. A. Lacasse, T. J. O'Connor and S. Nunes, P. Beaulieu, NRC (2003)

[5] L. Olsson, Journal of Building Physics, 41, no. 6, pp. 521-532 (2017)

[6] L. Olsson, Central Europe towards Sustainable Buildings (Prague, 2016)

[7] M. Lacasse, M. Rousseau, S. Cornick and S. Plescia, 10th Canadian Conference on Building Science \& Technology (Ottawa, 2005)

[8] Belgisch Insituut voor Normalisatie, NBN EN 12114 (2000)

[9] Belgisch Insituut voor Normalisatie, NBN EN 1027 (2016)

[10] ift-Rosenheim, ift-Richtlinie MO-01/1 (2007)

[11] N. Van Den Bossche, W. Huyghe, J. Moens, A. Janssens and M. Depaepe, Energy and buildings, 45, pp. 32-42 (2012)

[12] SBRCURnet, Luchtdicht bouwen: Theorie - ontwerp - praktijk (2013)

[13] Nederlands Instituut voor Normalisatie, NEN 2687:1989 (1989) 
[14] Belgisch Instituut voor Normalisatie, NBN EN 12208 (2000)

[15] Belgisch Instituut voor Normalisatie, prNBN B 25-002-1 (2017) 